\title{
Prenatal Exposure to Betamethasone Decreases Anxiety in Developing Rats: Hippocampal Neuropeptide $Y$ as a Target Molecule
}

\author{
Libor Velíšek*,1,2 \\ 'Departments of Neurology and Neuroscience, Albert Einstein College of Medicine, Bronx, NY, USA; ${ }^{2}$ Einstein/Montefiore Epilepsy Management \\ Center, Bronx, NY, USA
}

\begin{abstract}
Repeated antenatal administration of betamethasone is frequently used as a life-saving treatment in obstetrics. However, limited information is available about the outcome of this therapy in children. The initial prospective studies indicate that there are behavioral impairments in children exposed to repeated courses of prenatal betamethasone during the third trimester of pregnancy. In this study, pregnant rats received two betamethasone injections on day 15 of gestation. Using immunohistochemistry, the expression of a powerful anxiolytic molecule neuropeptide Y (NPY) was determined on postnatal day (PN) 20 in the hippocampus and basolateral amygdala (structures related to anxiety and fear) of the offspring. Prenatal betamethasone exposure induced significant increases in NPY expression in the hippocampus but not in the amygdala. Indeed, behavioral tests in the offspring, between PN20 and PN22 in the open field, on the horizontal bar, and in the elevated plus maze, indicated decreases in anxiety, without impairments in motor performance or total activity. Decreased body weight in betamethasone-exposed rats confirmed long-lasting effects of prenatal exposure. Thus, prenatal betamethasone treatment consistently increases hippocampal NPY, with decreases in anxiety-related behaviors and hippocampal role in anxiety in rats. Animal models may assist in differentiation between pathways of the desired main effect of the antenatal corticosteroid treatment and pathways of unwanted side effects. This differentiation can lead to specific therapeutic interventions directed against the side effects without eliminating the beneficial main effect of the corticosteroid treatment.
\end{abstract}

Neuropsychopharmacology (2006) 3 I, 2140-2 I49. doi: I0.1038/sj.npp. I 3010 I6; published online II January 2006

Keywords: repeated exposure; betamethasone; anxiety; neuropeptide Y; prenatal; immunohistochemistry

\section{INTRODUCTION}

Therapeutic administration of corticosteroids is used as a life-saving treatment to prevent respiratory distress syndrome in those pregnancy cases in which premature delivery is imminent. An NIH Consensus conference published the Statement in 1994 (NIH, 1994) indicating that one-time corticosteroid administration is safe and without side effects for prevention of respiratory distress syndrome in prematurely born neonates. This conclusion was based on numerous prospective studies after this treatment (NIH, 1994; MacArthur et al, 1981, 1982; Schmand et al, 1990; Smolders-de Haas et al, 1990). As a result, the trend in clinical practice has become to repeat the

*Correspondence: Dr L Velĩsek, Departments of Neurology and Neuroscience, Albert Einstein College of Medicine, K 314, 1410 Morris Park Avenue, Bronx, NY 1046I, USA, Tel: + I 718430 2490, Fax: + I 7I8 430 8899, E-mail: velisek@aecom.yu.edu

Received 2 August 2005; revised 16 November 2005; accepted 17 November 2005

Online publication: 25 November 2005 at http://www.acnp.org/ citations/Npp I | 2505050487/default.pdf administration of synthetic corticosteroids in pregnant women at risk for premature delivery if delivery does not occur within 7-10 days after the initial treatment $(\mathrm{NIH}$, 2000; French et al, 1999; Ng et al, 1999) making the exposure to synthetic corticosteroids long-lasting. As indicated by the follow-up NIH Consensus Statement in 2000, beneficial effects of multiple $v s$ single antenatal corticosteroid administration had not been proven by carefully controlled prospective studies, although animal studies have suggested a possible increase in side effects (NIH, 2000). Since the 2000 Consensus Conference, two prospective studies appeared. One study indicated that repeated antenatal synthetic corticosteroids (either betamethasone or dexamethasone) $v s$ a single treatment may increase intracerebral hemorrhage in neonates while not significantly improving the lung maturation outcome, and was terminated prematurely (Guinn et al, 2001). A recent prospective study (French et al, 2004) demonstrated that repeated prenatal betamethasone courses were associated with behavioral side effects. Affected children had increases in aggressive/destructive behavioral scores at 3 and 6 years of age. These children also displayed greater distractibility 
and hyperactivity, although their intellectual performance was not affected. Prospective human studies are laborintensive, time-consuming, and costly. Therefore, relevant animal studies may help in finding the methods of preserving desired life-saving main effects of antenatal corticosteroid treatments along with significant suppression of unwanted side effects.

Studies in rats reveal that surges of corticosteroids during critical developmental periods produce long-term impairments during postnatal life (Avishai-Eliner et al, 2002; Brunson et al, 2005; Matthews, 2000; Welberg and Seckl, 2001). Several different techniques were used and invariably caused detrimental effects on the offspring. Exposure of pregnant rats to $45 \mathrm{~min}$ of restraint stress in a cylinder three times a day during the third week of gestation was associated with increased corticosteroid levels. The offspring then displayed an enhanced response to the restraint stress (Barbazanges et al, 1996), and also displayed impairments of working memory in radial maze and spatial recognition memory in the $\mathrm{Y}$ maze (Vallee et al, 1999). Similarly, prenatal continuous corticosterone release from a pellet on days 16-21 of gestation (E16-21) induced both short- and long-term changes in spontaneous motor activity, such as increases in motility, rearing, and locomotion in the offspring (Diaz et al, 1997; Mickley et al, 1989). Even maternal corticosteroids, reaching the fetus in physiologic concentrations between E13 and E23 (owing to inhibition of maternal placental $11 \beta$-hydroxysteroid dehydrogenase type 2 enzyme), delayed puberty onset in the offspring (Smith and Waddell, 2000). Repeated administration of dexamethasone on E17-19 significantly decreased body and brain weight of newborn rats (Carlos et al, 1992). Finally, dexamethasone administration during the last (third) week of rat pregnancy decreased postnatal body weight in the offspring, reduced exploratory behavior both in an open field and in an elevated plus maze, and impaired behavioral responses and learning in a forcedswim test (Welberg et al, 2001). Previous studies from our laboratory demonstrated that prenatal exposure to two doses of $0.4 \mathrm{mg} / \mathrm{kg}$ of betamethasone on E15 decreased susceptibility to dentate gyrus kindling in immature postnatal day 15-16 (PN15-16) rats (Velíšek, 2005b).

Increased corticosteroids during critical developmental periods prenatally or early postnatally may impair postnatal behavior in the offspring (Avishai-Eliner et al, 2002; Matthews, 2000; Seckl et al, 2000). Therefore, we hypothesized that repeated prenatal exposures to synthetic betamethasone in rats will alter postnatal behavior, similar to human conditions after prolonged antenatal betamethasone exposure (French et al, 2004). As our data revealed changes in anxiety, we determined whether the prenatal exposure to betamethasone affects expression of neuropeptide Y (NPY), a peptide neurotransmitter with powerful anxiolytic effects (Heilig, 2004; Tschenett et al, 2003), in those brain areas associated with anxiety behaviors (Bannerman et al, 2004).

\section{MATERIALS AND METHODS}

\section{Animals and Prenatal Treatments}

Experiments were carried out according to the Revised Guide for the Care and Use of Laboratory Animals (NIH
GUIDE, volume 25, number 28, August 16, 1996). All experiments reported here were reviewed and approved by the Institutional Animal Care and Use Committee. Timed pregnant Sprague-Dawley rats were purchased from Taconic Farms (Germantown, NY, USA) and received on day 8 of pregnancy (E8).

Rats were housed in our AAALAC-approved facility, with free access to rat chow and tap water on a $12 \mathrm{~h}$ dark: light cycle with lights on at 0700 . On E15, all rats received two injections. The control group of pregnant rats was injected with normal saline $(1 \mathrm{ml} / \mathrm{kg}$ i.p.) at 0800 and 1800 . Another group of pregnant rats received two doses of betamethasone $(0.4 \mathrm{mg} / \mathrm{kg}$ i.p. in $1 \mathrm{ml} / \mathrm{kg}$ of normal saline) at the same times (ie $10 \mathrm{~h}$ apart). The treatment paradigm studied here in rats was intended to model prolonged antenatal corticosteroid exposure in humans. Pregnant women usually receive two doses of $12 \mathrm{mg}$ of betamethasone within $24 \mathrm{~h}$ as a standard treatment and this is considered as a single course of betamethasone therapy (French et al, 2004). With an average body weight of $60 \mathrm{~kg}$, this implies $2 \times 0.2 \mathrm{mg} / \mathrm{kg}$ of betamethasone within $24 \mathrm{~h}$. In pregnant women, betamethasone half-life is approximately $4.5 \mathrm{~h}$ (Petersen et al, 1983), so the interval between the doses is about five half-lives. In rats, betamethasone half-life is approximately $2 \mathrm{~h}$ (Tamvakopoulos et al, 2002). Thus, in our treatment paradigm in rats, we delivered twice as much betamethasone as in the human treatment paradigm, separated by five half-lives. Although we did not measure plasma concentrations, available data after a single i.v. injection of $1 \mathrm{mg} / \mathrm{kg}$ of betamethasone in rats show that after $2 \mathrm{~h}$ its plasma concentration is around $1 \mu \mathrm{M}$ and after $8 \mathrm{~h}$ it drops to $100 \mathrm{nM}$ (Tamvakopoulos et al, 2002). However, in women, $24 \mathrm{~h}$ after the last injection of betamethasone, the plasma concentration is approximately

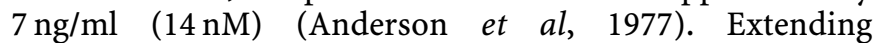
betamethasone metabolism in the rat using its biological half-life indicates that, after $24 \mathrm{~h}$, plasma concentrations in our rat treatment paradigm and in pregnant women are in a similar range. After injections, pregnant rats were kept in separate cages until day of delivery (PN0). On PN1, newborn rat pups were weighed, sexed, and the litters culled to five males and five females, if possible. It should be emphasized that no more than two males and two females from each litter were used and that a minimum of three litters per treatment group and behavioral experiment group were used to avoid 'litter' effects. For immunohistochemistry, two males and two females from two different litters per treatment group were used.

\section{Weight}

For the purpose of this study, weight was checked on PN15 and PN20. Weight of rats was used as a measure of biological activity of prenatally administered corticosteroids. Multiple studies have determined that prenatal exposure to corticosteroids decreases postnatal weight (Carlos et al, 1992; Scheepens et al, 2003). Here, the weight was determined repeatedly to assess whether in this model the weight loss is only transient (Scheepens et al, 2003) or lasts throughout the experimental period. 


\section{Behavioral Tests in the Offspring}

All behavioral tests were performed on PN20. For practical purposes, if possible, horizontal bar walking and elevated plus-maze tests were administered to the same rats: horizontal bar walking always before the elevated plusmaze test. Different rats on PN20 were used in the openfield test. Behavioral tests were performed blinded to experimental conditions.

Elevated plus maze (anxiety test; Pellow et al, 1985; Pellow and File, 1986). The elevated plus maze consisted of four arms $10 \times 50 \mathrm{~cm}$. Two contrapositioned arms were closed and two were open. All the arms were interconnected with a $10 \times 10 \mathrm{~cm}^{2}$ platform. The entire maze was positioned $60 \mathrm{~cm}$ above the ground. For enhanced contrast between open and closed arms, the ends of the open arms were illuminated by focused light sources. The rat (on PN20) was positioned at the distal end of one of the open arms facing out and released. Latency to enter the last third of the closed arm was measured (referred to as transfer latency (TL); Hlinak and Krejci, 2002). We chose to use the entry into the last third of the closed arm, to skew the measurement toward the indication of anxiety in contrast to simple exploratory activity. Before each test, the plastic elevated plus maze was cleaned with $70 \%$ alcohol and left to dry out.

Elevated plus maze (memory retention test). Repeated testing serves as a measure of memory retention (Hlinak and Krejci, 2002; Itoh et al, 1991; Onodera et al, 1998; Podhorna and Franklin, 1998). Transfer latency was determined repeatedly on 3 consecutive days (PN20-22). Thus, a memory component should play a role in the repeated tests. Changes in transfer latency over this 3-day period were expressed in terms of retention index (RI; Kábová et al, 1999). In this study, the RI was calculated as $\mathrm{RI}=\log \left(\mathrm{TL}_{\mathrm{PN} 20}\right)-\log \left(\mathrm{TL}_{\mathrm{PN} 22}\right)$. The $\mathrm{RI}$ value indicates whether the performance improves over time $(\mathrm{RI}>0)$, whether the performance decreases $(\mathrm{RI}<0)$, or whether there is no change in performance $(\mathrm{RI}=0)$.

Horizontal bar walking. This is a measure of motor skills in a highly motivating environment (Murphy et al, 1995). The rat was positioned perpendicularly to the $2 \mathrm{~cm}$ diameter bar hanging $50 \mathrm{~cm}$ above the padded floor and allowed to grasp first with the front paws and then also with the hind paws. At that moment, the rat was released and the timing was started. Time limit for horizontal bar walking was set to $2 \mathrm{~min}$. Three tests were performed per one session and the best result was used for the evaluation.

Open-field activity. Several parameters were determined using an automated open field (Med-Associates, St Albans, VT, USA) with area dimensions $42.5 \times 42.5 \mathrm{~cm}$ within a 5 min session time. In this open field, the central area was defined (by means of software) as $22.5 \times 22.5 \mathrm{~cm}$ in the middle of the field (area of $506.25 \mathrm{~cm}^{2} ; 28 \%$ of total openfield area). Periphery consisted of a $10 \mathrm{~cm}$ wide area along the walls. Distance and time traveled (ambulation), time spent with stereotypies, time spent resting, and time spent rearing, as well as counts of the number of events were evaluated during the entire session. The fraction of activities related to the central area $\left(F_{\text {central }}=\right.$ central area value/total value) was also calculated. Additionally, total number of entries into the zones (zone crossings) and the relative time spent in the central zone were compared. Between the testings, the open field was wiped with $70 \%$ alcohol and left to dry out.

Immunohistochemistry. Littermates of the rats used in behavioral experiments were anesthetized with $50 \mathrm{mg} / \mathrm{kg}$ of pentobarbital i.p. and transcardially perfused with $4 \%$ paraformaldehyde. After sucrose cryoprotection, coronal sections were cut at $40 \mu \mathrm{m}$ through the entire hippocampus. Thus, some sections contained both dorsal and ventral hippocampus and also amygdala. Mainly ventral, but also dorsal hippocampus is related to anxiety behaviors, whereas basolateral amygdala is more connected with fear than with anxiety (Bannerman et al, 2004). For NPY immunostaining, free-floating sections $(40 \mu \mathrm{m})$ were collected every $200 \mu \mathrm{m}$. Sections were incubated for $1 \mathrm{~h}$ in $10 \%$ bovine serum albumin (BSA)/phosphate-buffered saline (PBS) solution to block nonspecific staining. The primary rabbit anti-NPY polyclonal antibody $(1: 2000$; Sigma, St Louis, MO, USA) was diluted in $4 \%$ BSA/PBS and the sections were incubated at $4^{\circ} \mathrm{C}$ for $24 \mathrm{~h}$. After several rinses, the immunoreactive neurons were visualized with $3^{\prime}-3^{\prime}$-diaminobenzidine using the avidin-biotin-horseradish peroxidase method (Vectastain $A B C$ kit, Vector Labs, Burlingame, CA, USA). To minimize differences between the various sets of stained sections, all sections were treated exactly the same way at all steps, and slices from prenatally saline- and betamethasone-exposed rats were stained in the same dish.

Control sections were prepared using the primary antiserum preadsorbed with the peptide or by incubating the sections without the primary antibodies: under both conditions, the immunohistochemical procedure failed to show any immunoreactivity.

\section{NPY Expression}

We used immunointensity measurement procedure described previously (Ravizza et al, 2003, 2002). Measurements were performed blinded to experimental conditions.

Selection of the sections. On the first microscopic slide containing the studied structure, one section was selected at random. At subsequent slides, we used the section determined by adding the number of sections per slide to the order number of the initial section. As there was a constant number of sections per slide, the sections throughout the structure were evaluated at regular intervals, however with a random beginning.

Regions. In the dorsal hippocampus, the area of the subgranular NPY-immunopositive neurons, the area of the inside hilar NPY-immunopositive neurons, and finally CA1 immunopositive neurons were investigated. Similarly, in the ventral hippocampus, we determined NPY expression within the hilus. Finally, we assessed NPY expression in basolateral amygdala. 
Measurements. On each section in each studied area (eg the subgranular zone of the dorsal hippocampus), 3-6 regions of interest (ROI; defined as a microscopy field at $\times 400$ magnification containing at least three NPY-immunopositive neurons) were digitally scanned. Within each ROI, immunoexpression of NPY in these three neurons was measured and expressed as a gray scale value using ImageJ software (Wayne Rasband; NIH). Similarly, gray scale values of three areas of background containing no cells and obvious fibers were measured. The values for background were averaged and the average was subtracted from the gray scale value for each neuron within the same ROI.

A total of 4-5 sections were evaluated per each structure and rat. In each region, immunointensity values were averaged for all measured neurons in each rat. Final averaged values (note that each rat contributed only one value per studied region computed from 35 to 90 individual neuronal measurements) were statistically compared.

\section{RESULTS}

\section{Body Weight}

We determined the body weight of the offspring during the postnatal testing period PN15-20 as an indicator of longterm biological effects of prenatal betamethasone exposure. At both ages (PN15 and PN20), prenatally betamethasoneexposed rats had lower body weight compared to prenatally saline-exposed rats. There was no sex-based body weight difference, and no interaction between the two factors (Figure 1). Decreases in postnatal body weight indicate long-term effects of prenatal betamethasone exposure

\section{Elevated Plus Maze: Anxiety Test}

In the elevated plus maze, betamethasone-exposed rats $(n=12)$ had longer transfer latency than prenatally salineexposed rats $\left(n=19\right.$; two-way ANOVA; $\mathrm{F}_{(1,27)}=4.604$; $P<0.05)$. Additionally, female rats $(n=19)$, regardless of the treatment, had longer transfer latency than male rats $\left(n=12 ; \mathrm{F}_{(1,27)}=4.246 ; P<0.05\right)$. Thus, prenatally betamethasone-exposed rats as well as female rats spent more time traveling from the open arm to the end of the closed arm, indicating a decrease in anxiety in these two groups compared to respective controls (Figure 2). There was no interaction between the two factors.

\section{Elevated Plus Maze: Memory Retention Index}

Repeated testing (three sessions over 3 days) in the elevated plus maze made it possible to calculate a retention index. In this measure, there was no difference between prenatally betamethasone-exposed and saline-exposed rats or between males and females (data not illustrated). All index values were positive numbers, indicating that some memory retention occurred with repeated elevated plus-maze testing.

\section{Horizontal Bar}

As the latency to reach the closed arm in the elevated plusmaze test may be a function of impaired motor performance and not anxiety, the rats, on PN20, were tested on the

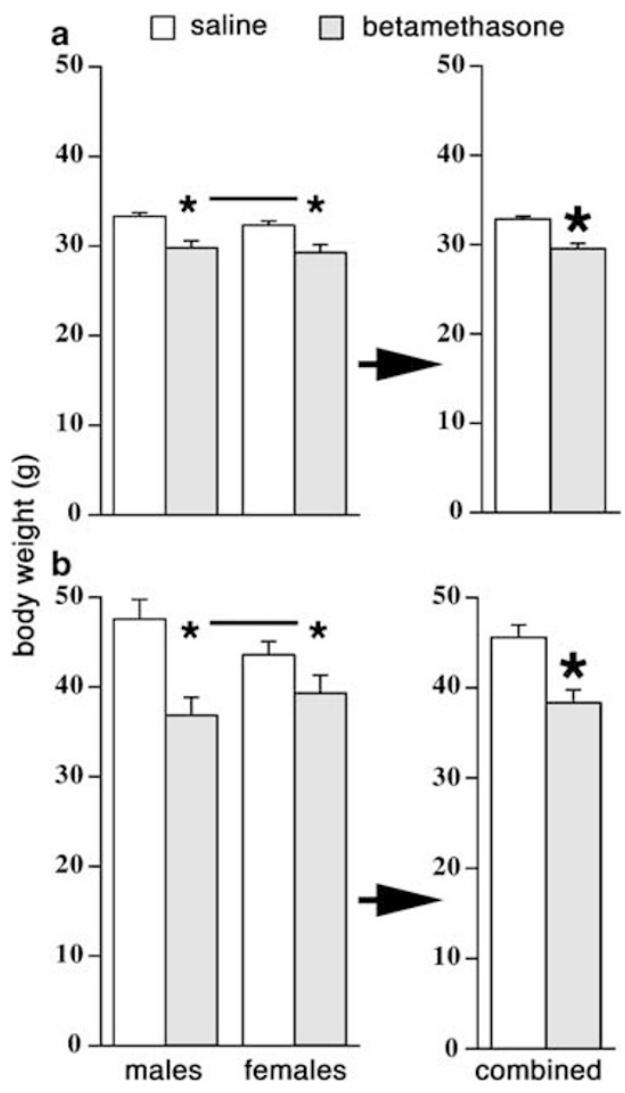

Figure I Prenatal betamethasone exposure significantly decreases postnatal body weight in the offspring. (a) PNI5. The left part of the figure shows body weight in prenatally betamethasone- and saline-exposed male and female rats (in g, $M \pm S E M$ ). Two stars with a bar indicate a significant difference between the treatments (see combined male + female data on the right). (b) Body weight at PN20 (in g, $M \pm S E M$ ). The difference between treatments still persists. At both ages, there were no sex differences in body weight. Findings indicate long-term biological effects of prenatal betamethasone exposure.

horizontal bar. No difference was found between the factors of prenatal treatment (betamethasone $n=9$; saline $n=21$; two-way ANOVA; $\mathrm{F}_{(1,26)}=1.819 ; P \gg 0.05$ ) and sex (two-way ANOVA; $\mathrm{F}_{(1,26)}=0.010 ; P \gg 0.05$; Figure 3, left). Re-calculating of combined male $(n=14)$ and female $(n=16)$ data using Student's $t$-test (factor: prenatal treatment) did not reveal any significant differences either $(P=0.158$; Figure 3 , right). As there was a significant body weight difference between the groups and, thus, holding on the horizontal bar may have been affected, body weight was introduced as a covariate into the two-way ANOVA. Correction for weight did not change the statistical outcome for the main factors and did not create any significant interaction. Thus, body weight can be excluded as a possible variable for horizontal bar holding time, and there was no effect of prenatal betamethasone exposure on horizontal bar holding.

\section{Open Field}

In the open-field testing, we focused on the following variables: total traveled distance-a difference would indicate motor problems (such as ataxia or poor walking skills) in one of the tested groups. Data analysis of this 


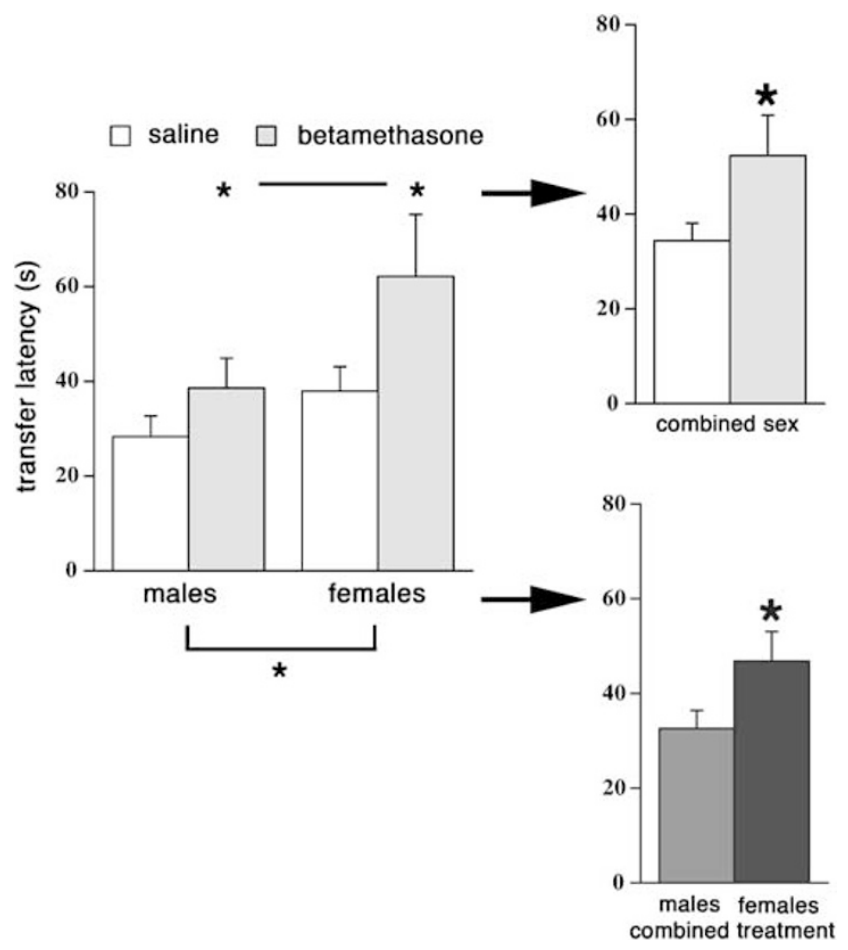

Figure 2 Transfer latency in the elevated plus maze (in s; $M \pm S E M$ ). The experiment was performed at PN20. The left side illustrates groups according to sex and treatment. There were significant effects of treatment (two asterisks with a bar) and sex (an asterisk with a horizontal bracket): betamethasone exposure increased the transfer latency and decreased anxiety. Additionally, females displayed less anxiety than males. Effects of both factors are individually shown on the right (treatment on the top; sex on the bottom).

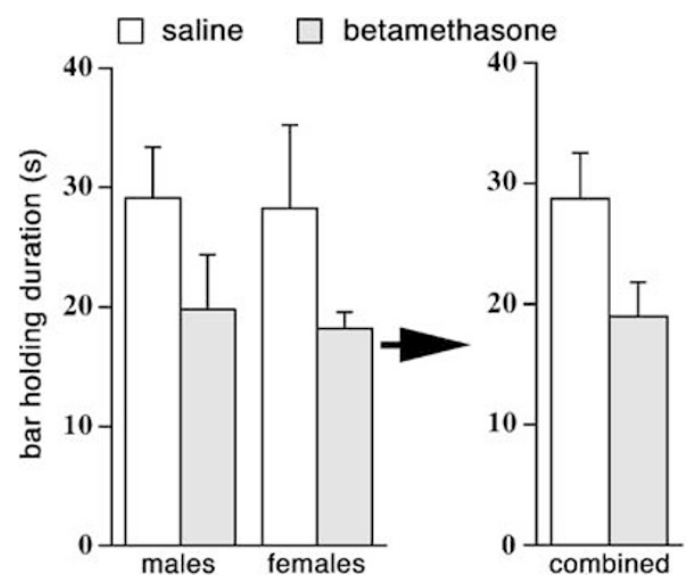

Figure 3 Duration of hold on the horizontal bar (in $s$; $M \pm S E M$ ). Performance at PN20. Despite the trend, there was no significant difference due to prenatal treatment or sex. Combining males with females did not bring any significance for the treatment effect (right side). Introduction of body weight as covariate also did not change the outcome of statistical tests.

variable did not reveal any significant difference as a function of prenatal treatment (two-way ANOVA; $P>0.95$ ) or sex. Distance traveled in the central field - this variable indicates a preference of the group for the central area of the open field (anti-agoraphobic behavior). Rats prenatally exposed to betamethasone $(n=16)$ traveled longer distance
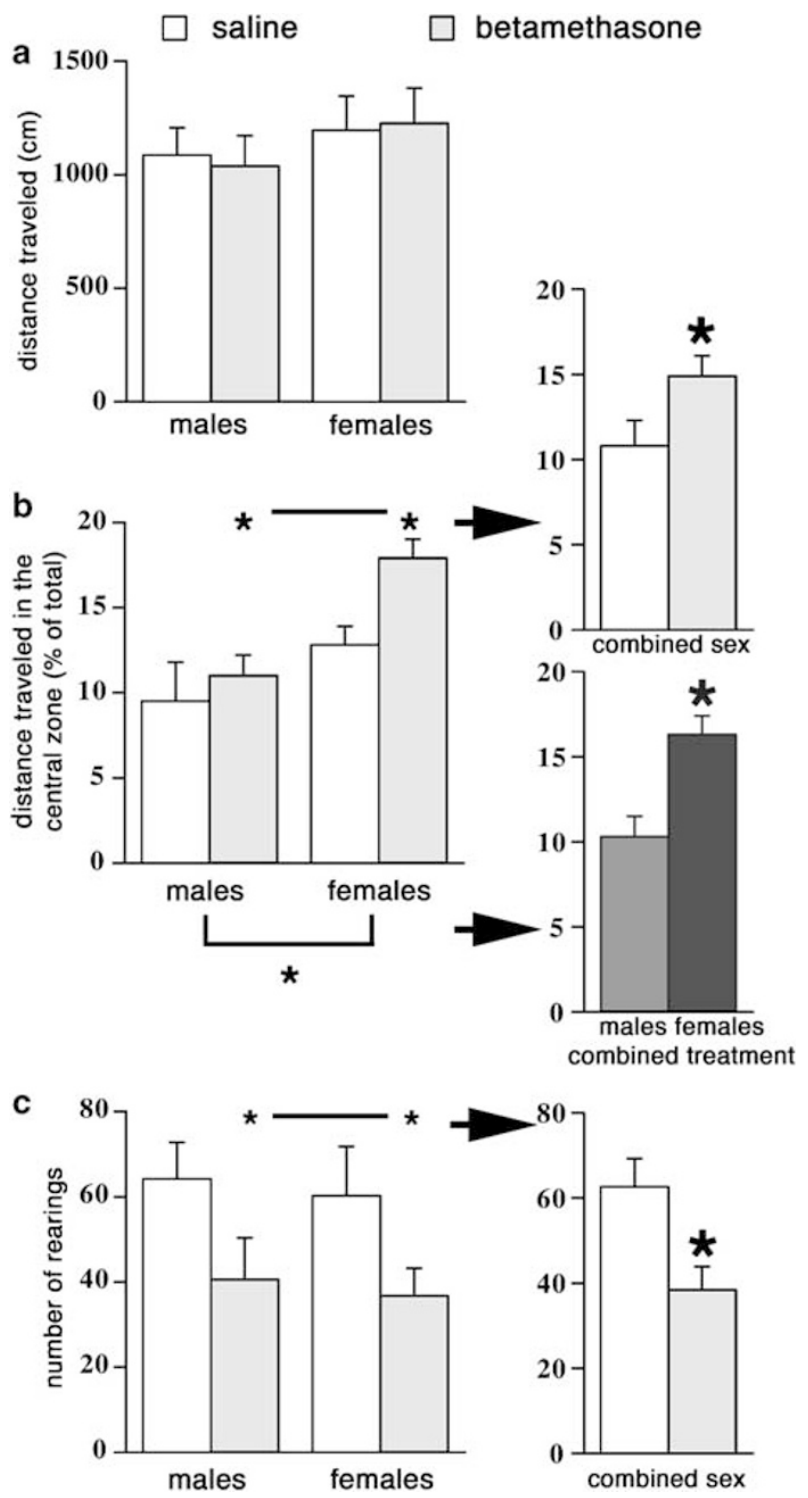

Figure 4 Open-field performance. (a) Total distance traveled within a 5 min session (in $\mathrm{cm} ; \mathrm{M} \pm \mathrm{SEM}$ ). There was no difference based on prenatal treatment or sex. All rats were approximately equally active in the open field. (b) Distance traveled in the central area (in \% of total distance traveled). There was a significant increase in traveling in the central area of the open field after betamethasone exposure (two asterisks with a bar) as well as in females (an asterisk with a horizontal bracket). Both factors are summarized on the right. The finding of increased travel in the central field is consistent with decreased anxiety and corresponds to the finding in the elevated plus maze (Figure 2). (c) Total number of rearings per $5 \mathrm{~min}$ session. There was a significant decrease in the rearing rate in betamethasone- compared to saline-exposed rats (two asterisks with a bar). There was no effect of sex. Here, a decrease in rearings is interpreted as a decrease in anxiety (see Discussion for technical considerations).

in the central area compared to saline-exposed rats $(n=10$; two-way ANOVA; $\mathrm{F}_{(1,22)}=4.315 ; P<0.05$; Figure $\left.4 \mathrm{a}\right)$. Similarly, female rats $(n=13)$ traveled a longer distance in the central area than male rats $(n=13$; two-way ANOVA; $\mathrm{F}_{(1,22)}=10.221 ; P<0.05$; Figure $\left.4 \mathrm{~b}\right)$. Finally, we evaluated rearing per session period. Prenatally betamethasoneexposed rats displayed significantly fewer rearing episodes than saline-exposed rats (two-way ANOVA; $\mathrm{F}_{(1,22)}=6.655$; 
$P<0.05$; Figure 4c). There was no difference between males and females and no interaction of the main effects. Other parameters such as number and duration of stereotypies or number of zone crossings were not different between prenatally exposed groups. Prenatally betamethasone-exposed rats tended to spend more time in the central field than prenatally saline-exposed rats (not illustrated), but this trend was not significant. Thus, the data show that there are differences in anxiety behavior between prenatally betamethasone- and saline-exposed rats.

\section{NPY Expression}

As NPY is connected with anxiety behaviors and its expression can be modified by corticosteroids, we determined NPY expression in those brain sites linked to anxiety and fear. First, in the hilus of the dentate gyrus of the ventral hippocampus, there was a significant increase in NPY expression in betamethasone- compared to salineexposed rats (two-way ANOVA; $\mathrm{F}_{(1,10)}=5.432 ; P<0.05$; Figure 5a). There was no difference between males and females and no interaction between the factors. Combined data irrespective of sex are shown in Figure 5a (right). There was higher NPY expression in the cells of prenatally betamethasone-exposed rats (Figure $5 \mathrm{~b}$ ) compared to saline-exposed rats (Figure 5c). In the basolateral amygdala,
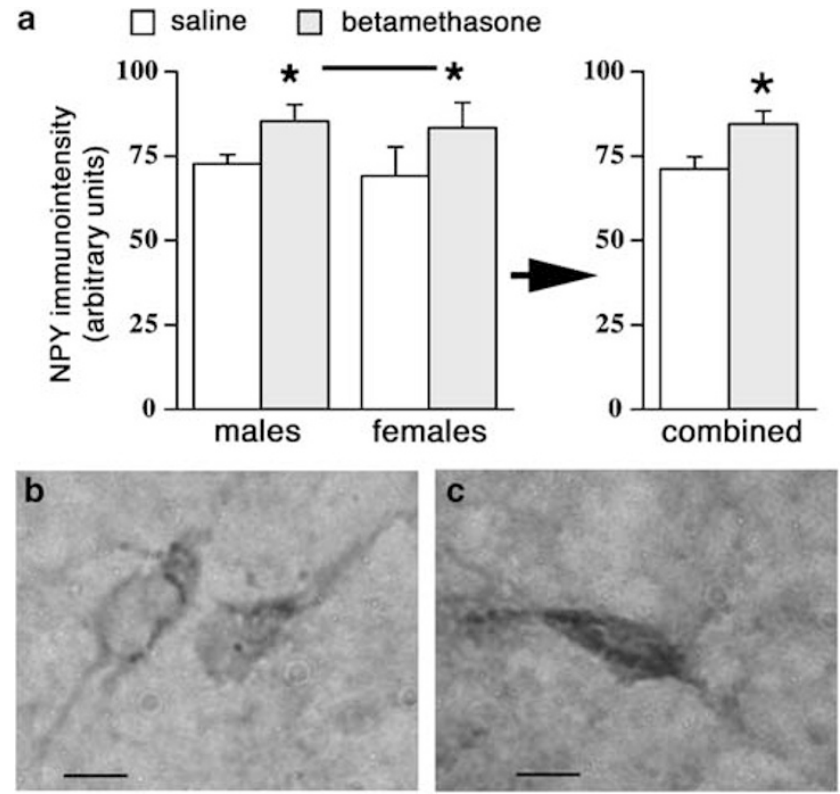

Figure 5 NPY immunoexpression in the dentate gyrus of the ventral hippocampus. (a) NPY immunointensity (arbitrary units; $M \pm S E M)$. Prenatal betamethasone exposure was associated with significantly increased NPY immunoexpression (two asterisks with a bar). There was no effect of sex. Combined male and female data are displayed on the right side. (b) Microphotograph at $\times 400$ magnification of two dentate gyrus neurons containing NPY in prenatally saline-exposed rat. Note the low level of NPY expression in the neurons as well as in the processes. Bar $=10 \mu \mathrm{m}$. (c) Microphotograph at $\times 400$ magnification of a dentate gyrus neuron containing NPY in prenatally betamethasone-exposed rats. NPY expression is high both in the neuron and in the processes. Background containing no processes is similar to background in (b), though. Immunohistochemical staining on saline- and betamethasone-exposed slices was run in the same dish for similar conditions. Bar $=10 \mu \mathrm{m}$. there was no effect of prenatal treatment (two-way ANOVA; $\mathrm{F}_{(1,10)}=3.635 ; P>0.05$; not illustrated). Similarly, there was no effect of sex and no interaction between the main effects. After combining data irrespective of sex and re-calculating with Student's $t$-test (factor: prenatal treatment), there was still no difference (not illustrated). Finally, we investigated three areas of the dorsal hippocampus: inner hilus and subgranular zone of the hilus as well as the CA1. In both the inner hilus and the subgranular zone, betamethasoneexposed rats had higher NPY expression (inner hilus, two-way ANOVA, $\mathrm{F}_{(1,10)}=10.618, \quad P<0.05$, Figure 6a;
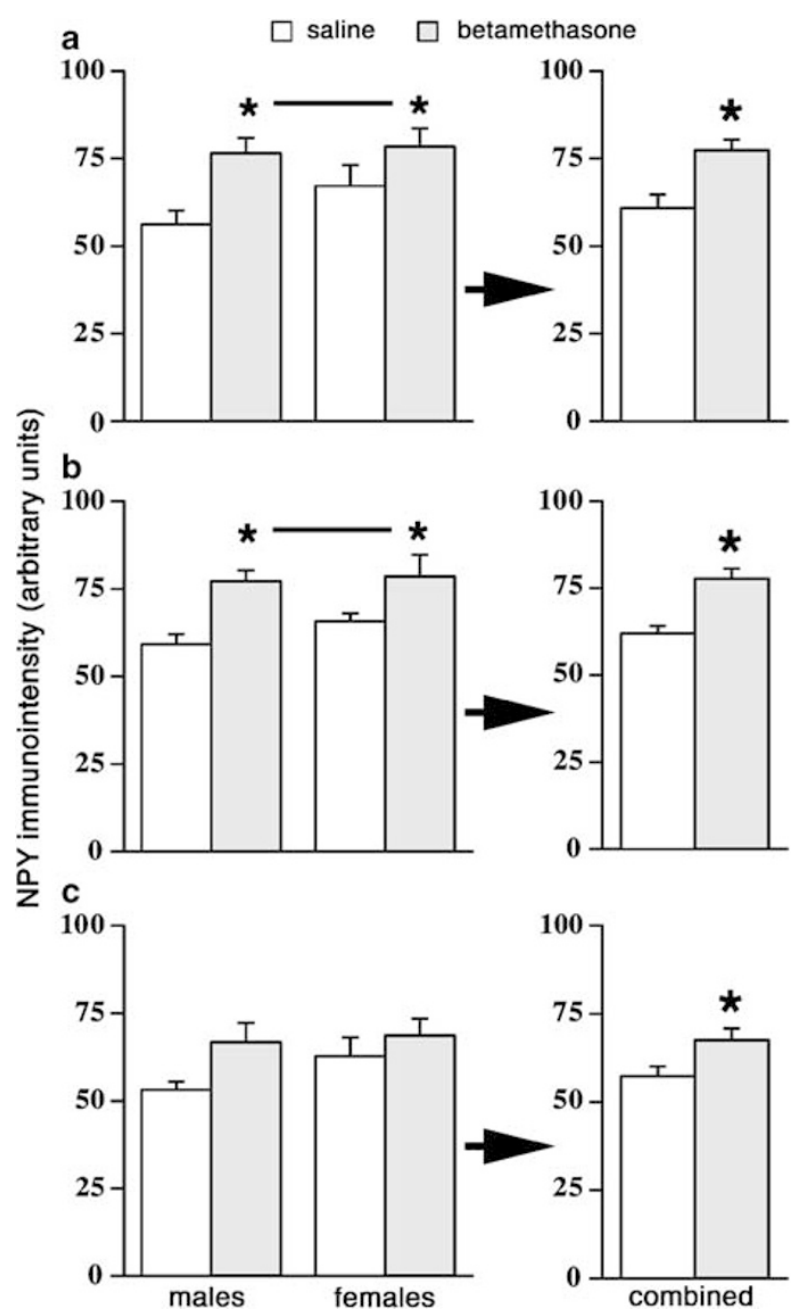

Figure 6 NPY immunoexpression in the dorsal hippocampus. (a) NPY immunointensity (arbitrary units; $\mathrm{M} \pm \mathrm{SEM}$ ) in the population of inner hilar NPY-containing neurons. Prenatal betamethasone exposure was associated with increased NPY immunoexpression (two asterisks with a bar). As no sex difference was found, combined data are shown on the right. (b) NPY immunointensity (arbitrary units; $M \pm S E M$ ) in the population of subgranular NPY-containing neurons. Prenatal betamethasone exposure was associated with increased NPY immunoexpression (two asterisks with a bar). As no sex difference was found, combined data are shown on the right. (c) NPY immunointensity (arbitrary units; $M \pm S E M$ ) in the population of CAI neurons. Two-way ANOVA did not reveal any difference based on pretreatment or sex. When combined male and female data were compared with Student's t-test, prenatal betamethasone exposure was associated with increased NPY immunointensity (right). Although we did not perform cell counts, NPY-containing neurons appeared to be more numerous in prenatally betamethasone-exposed rats (Velišek, 2005a). 
subgranular zone, two-way ANOVA, $\mathrm{F}_{(1,10)}=17.653, P<0.05$, Figure $6 \mathrm{~b})$. No differences were found based on the sex of rats or interaction of factors in these two areas. Combined data irrespective of sex are shown on the right side of Figure $6 \mathrm{a}$ and $\mathrm{b}$. In the CA1 area, there was no significant difference between the betamethasone- and salineexposed groups (two-way ANOVA; $\mathrm{F}_{(1,10)}=4.334 ; P>0.05$; Figure 6c) despite the trend to increased NPY expression in betamethasone-exposed rats. As no effect of sex as well as no interaction between the main factors was found, the data were combined irrespective of sex and re-analyzed using Student's $t$-test (factor: prenatal exposure). This trend then became significantly different $(P<0.05$; Figure $6 c$, right).

\section{DISCUSSION}

Our results demonstrate that prenatal exposure to repeated betamethasone on E15 in the rat is associated with increased expression of NPY in both ventral and dorsal hippocampus but not in the basolateral amygdala. This prenatal exposure also results in decreased anxiety corroborated in two independent tests carried out in the elevated plus maze and in the open field using three different variables (transfer latency, central area ambulation, and rearing). Because NPY has anxiolytic features, we propose that decreases in anxiety after prenatal betamethasone exposure are due to increased expression of NPY in the hippocampus, a structure associated with anxiety behaviors.

\section{Technical Considerations}

In this study, we chose to test anxiety in the elevated plus maze using the transfer latency measure. This approach enabled us to perform repeated tests over 3 days and also study memory involvement. Thus, the first daily session served as an anxiety trial, whereas repeated sessions were used for memory testing. The disadvantage of this approach compared to the recording of entries to the open and closed arms from the central platform is that 'freezing' of the rat on the open arm would give a false impression of decreased anxiety (due to enhanced transfer latency). However, as the open field was used for measurements of mobility and no difference was found between the groups, this objection can be dismissed.

Second, the interpretation of rearing is ambiguous. Some studies consider decreased rearing counts as a measure of increased anxiety (Welberg et al, 2001) and others as a measure of decreased anxiety (Broderick et al, 1998; Masood et al, 2003; McGregor et al, 2004). However, increased rearing rate correlates with increased arterial blood pressure and decreased locomotor activity in the cat odor anxiety test in rats (Dielenberg and McGregor, 2001; McGregor et al, 2004), thus providing a convincing correlation between increased rearing and increased anxiety. Findings of this study were interpreted accordingly.

This study indicates that NPY may serve as one of the downstream regulator molecules of prenatal betamethasone exposure with effects on behavior. Although we did not demonstrate causality, only association of NPY with behavioral effects, multiple studies have already determined anxiolytic effects of NPY (for a review, see Heilig, 2004). Increased NPY expression or NPY administration is associated with anxiolytic effects, whereas decreased NPY expression or blockade of its receptors is anxiogenic (Bannon et al, 2000; Heilig and Murison, 1987; Sajdyk et al, 1999; Sorensen et al, 2004; Tschenett et al, 2003). Accordingly, increased NPY expression in the hippocampus after prenatal betamethasone exposure is congruent with anti-anxiety effects. Increased expression of NPY (which also has anticonvulsant features; Richichi et al, 2004) in the hippocampus may also help in explaining the slower dentate gyrus kindling rate in betamethasone-exposed immature rats compared to saline-exposed rats in our previous study (Velíšek, 2005b). Earlier studies have shown that mainly ventral but also dorsal hippocampus is involved in anxiety control (Andrews et al, 1997; Bannerman et al, 2002a, b, 2003; Gonzalez et al, 1998; Kjelstrup et al, 2002; McHugh et al, 2004) and NPY alterations in the hippocampus affect anxiety behaviors (Heilig, 2004; Thorsell et al, 2000). We did not see an increase in NPY expression in the basolateral amygdala; however, lesion studies have demonstrated that this region does not participate in the anxiety behavior tested in the elevated plus maze (Gonzalez et al, 1996; Treit et al, 1993), and that the amygdala is rather associated with fear control (Bannerman et al, 2004).

Although the association of NPY with prenatal betamethasone exposure is shown here, NPY may not necessarily be the only target molecule. Prenatal corticosteroid exposure downregulates hippocampal glucocorticoid receptors (Welberg et al, 2001), which also play a role in anxiety (Tronche et al, 1999). Additionally, the hippocampus contains corticotropin-releasing hormone (Chen et al, 2004; Yan et al, 1998), which may be altered by prenatal corticosteroid exposure and is involved in anxiety control (Stenzel-Poore et al, 1994).

Behavioral findings presented here are in contrast with the studies evaluating the effects of prenatal stress (Vallee et al, 1997) on postnatal behavior. In these studies however, endogenous corticosteroids as well as the entire HPA axis are activated, and this may account for differential results. We also found different outcomes than the previous study (Welberg et al, 2001) describing an increase in anxiety after prenatal exposure to dexamethasone. Several factors may have contributed to these differences. First, the abovementioned study used a long-term treatment paradigm covering the entire third week of pregnancy in the rat. Second, as dexamethasone was used for treatment, the outcome may be different from betamethasone. Structural differences between dexamethasone and betamethasone were shown to affect apoptotic activity (Perrin-Wolff et al, 1995). Finally, mobility of the dexamethasone-exposed rats may have been overall compromised (Welberg et al, 2001) as corroborated by a different study using PN3-6 exposure to dexamethasone (Neal et al, 2004). This was not the case in our experiment with betamethasone.

The present study demonstrates that repeated prenatal exposure to betamethasone may significantly affect postnatal behaviors in rats. This is in agreement with other studies, which demonstrated behavioral alterations after prenatal exposure to exogenous corticosteroids (for a review, see Aghajafari et al, 2002), induction of maternal stress (Barbazanges et al, 1996; Reznikov et al, 1999; 
Takahashi et al, 1998; Vallee et al, 1997, 1999), or after enhanced penetration of maternal corticosteroids to the fetus (Welberg et al, 2000). As behavioral problems may also occur in children exposed to severe prenatal stress or repeated administration of betamethasone (French et al, 1999, 2004; Stott, 1973), continuing research is necessary to determine the mechanisms of the behavioral side effects (Avishai-Eliner et al, 2002; Matthews, 2000; Seckl, 2000; Seckl et al, 2000; Welberg and Seckl, 2001). As corticosteroids may utilize multiple pathways for their actions (Beato and Sanchez-Pacheco, 1996; De Kloet, 2004; Makara and Haller, 2001; Meijer, 2002), it is reasonable to anticipate that the mechanisms responsible for the beneficial and desired effects of prenatal betamethasone (lung maturation) are distinct from mechanisms responsible for unwanted side effects on behavior. This model may help in defining pathways of prenatal betamethasone actions and selecting those in which a specific therapeutic intervention would prevent unwanted side effects. Thus, by understanding different corticosteroid pathways, preventative or therapeutic measures against the side effects will become possible.

\section{ACKNOWLEDGEMENTS}

This study was supported by NIH Grants NS-41366 and NS-20253 and Heffer Family Medical Foundation. I thank Ms Zunju $\mathrm{Hu}$ for excellent technical assistance and Dr Henry Hasson for critical reading of the manuscript. Dr Jana Velíšková's help with NPY densitometry and critical reading of the manuscript is deeply appreciated.

\section{REFERENCES}

Aghajafari F, Murphy K, Matthews S, Ohlsson A, Amankwah K, Hannah M (2002). Repeated doses of antenatal corticosteroids in animals: a systematic review. Am J Obstet Gynecol 186: 843-849.

Anderson AB, Gennser G, Jeremy JY, Ohrlander S, Sayers L, Turnbull AC (1977). Placental transfer and metabolism of betamethasone in human pregnancy. Obstet Gynecol 49: 471-474.

Andrews N, File SE, Fernandes C, Gonzalez LE, Barnes NM (1997). Evidence that the median raphe nucleus - dorsal hippocampal pathway mediates diazepam withdrawal-induced anxiety. Psychopharmacology (Berl) 130: 228-234.

Avishai-Eliner S, Brunson KL, Sandman CA, Baram TZ (2002). Stressed-out, or in (utero)? Trends Neurosci 25: 518-524.

Bannerman DM, Deacon RM, Offen S, Friswell J, Grubb M, Rawlins JN (2002a). Double dissociation of function within the hippocampus: spatial memory and hyponeophagia. Behav Neurosci 116: 884-901.

Bannerman DM, Grubb M, Deacon RM, Yee BK, Feldon J, Rawlins JN (2003). Ventral hippocampal lesions affect anxiety but not spatial learning. Behav Brain Res 139: 197-213.

Bannerman DM, Lemaire M, Yee BK, Iversen SD, Oswald CJ, Good MA et al (2002b). Selective cytotoxic lesions of the retrohippocampal region produce a mild deficit in social recognition memory. Exp Brain Res 142: 395-401.

Bannerman DM, Rawlins JN, McHugh SB, Deacon RM, Yee BK, Bast $\mathrm{T}$ et al (2004). Regional dissociations within the hippocampus-memory and anxiety. Neurosci Biobehav Rev 28: 273-283.

Bannon AW, Seda J, Carmouche M, Francis JM, Norman MH, Karbon B et al (2000). Behavioral characterization of neuropeptide Y knockout mice. Brain Res 868: 79-87.
Barbazanges A, Piazza PV, Le Moal M, Maccari S (1996). Maternal glucocorticoid secretion mediates long-term effects of prenatal stress. J Neurosci 16: 3943-3949.

Beato M, Sanchez-Pacheco A (1996). Interaction of steroid hormone receptors with the transcription initiation complex. Endocr Rev 17: 587-609.

Broderick PA, Hope O, Jeannot P (1998). Mechanism of triazolobenzodiazepine and benzodiazepine action in anxiety and depression: behavioral studies with concomitant in vivo CA1 hippocampal norepinephrine and serotonin release detection in the behaving animal. Prog Neuropsychopharmacol Biol Psychiatry 22: 353-386.

Brunson KL, Kramar E, Lin B, Chen Y, Colgin LL, Yanagihara TK et al (2005). Mechanisms of late-onset cognitive decline after early-life stress. J Neurosci 25: 9328-9338.

Carlos RQ, Seidler FJ, Slotkin TA (1992). Fetal dexamethasone exposure alters macromolecular characteristics of rat brain development: a critical period for regionally selective alterations? Teratology 46: 45-59.

Chen Y, Brunson KL, Adelmann G, Bender RA, Frotscher M, Baram TZ (2004). Hippocampal corticotropin releasing hormone: pre- and postsynaptic location and release by stress. Neuroscience 126: 533-540.

De Kloet ER (2004). Hormones and the stressed brain. Ann NY Acad Sci 1018: 1-15.

Diaz R, Fuxe K, Ogren SO (1997). Prenatal corticosterone treatment induces long-term changes in spontaneous and apomorphine-mediated motor activity in male and female rats. Neuroscience 81: 129-140.

Dielenberg RA, McGregor IS (2001). Defensive behavior in rats towards predatory odors: a review. Neurosci Biobehav Rev 25: 597-609.

French NP, Hagan R, Evans SF, Godfrey M, Newnham JP (1999). Repeated antenatal corticosteroids: size at birth and subsequent development. Am J Obstet Gynecol 180: 114-121.

French NP, Hagan R, Evans SF, Mullan A, Newnham JP (2004). Repeated antenatal corticosteroids: effects on cerebral palsy and childhood behavior. Am J Obstet Gynecol 190: 588-595.

Gonzalez LE, Andrews N, File SE (1996). 5-HT1A and benzodiazepine receptors in the basolateral amygdala modulate anxiety in the social interaction test, but not in the elevated plus-maze. Brain Res 732: 145-153.

Gonzalez LE, Ouagazzal AM, File SE (1998). Stimulation of benzodiazepine receptors in the dorsal hippocampus and median raphe reveals differential GABAergic control in two animal tests of anxiety. Eur J Neurosci 10: 3673-3680.

Guinn DA, Atkinson MW, Sullivan L, Lee M, MacGregor S, Parilla BV et al (2001). Single vs weekly courses of antenatal corticosteroids for women at risk of preterm delivery: a randomized controlled trial. JAMA 286: 1581-1587.

Heilig M (2004). The NPY system in stress, anxiety and depression. Neuropeptides 38: 213-224.

Heilig M, Murison R (1987). Intracerebroventricular neuropeptide Y suppresses open field and home cage activity in the rat. Regul Pept 19: 221-231.

Hlinak Z, Krejci I (2002). MK-801 induced amnesia for the elevated plus-maze in mice. Behav Brain Res 131: 221-225.

Itoh J, Nabeshima T, Kameyama T (1991). Utility of an elevated plus-maze for dissociation of amnesic and behavioral effects of drugs in mice. Eur J Pharmacol 194: 71-76.

Kábová R, Liptáková S, Šlamberová R, Pometlová M, Velíšek L (1999). Age-specific $N$-methyl-D-aspartate-induced seizures: perspectives for the West syndrome model. Epilepsia 40: 13571369.

Kjelstrup KG, Tuvnes FA, Steffenach HA, Murison R, Moser EI, Moser MB (2002). Reduced fear expression after lesions of the ventral hippocampus. Proc Natl Acad Sci USA 99: $10825-10830$ 
MacArthur BA, Howie RN, Dezoete JA, Elkins J (1981). Cognitive and psychosocial development of 4-year-old children whose mothers were treated antenatally with betamethasone. Pediatrics 68: 638-643.

MacArthur BA, Howie RN, Dezoete JA, Elkins J (1982). School progress and cognitive development of 6-year-old children whose mothers were treated antenatally with betamethasone. Pediatrics 70: 99-105.

Makara GB, Haller J (2001). Non-genomic effects of glucocorticoids in the neural system. Evidence, mechanisms and implications. Prog Neurobiol 65: 367-390.

Masood A, Banerjee B, Vijayan VK, Ray A (2003). Modulation of stress-induced neurobehavioral changes by nitric oxide in rats. Eur J Pharmacol 458: 135-139.

Matthews SG (2000). Antenatal glucocorticoids and programming of the developing CNS. Pediatr Res 47: 291-300.

McGregor IS, Hargreaves GA, Apfelbach R, Hunt GE (2004). Neural correlates of cat odor-induced anxiety in rats: regionspecific effects of the benzodiazepine midazolam. J Neurosci 24: 4134-4144.

McHugh SB, Deacon RM, Rawlins JN, Bannerman DM (2004). Amygdala and ventral hippocampus contribute differentially to mechanisms of fear and anxiety. Behav Neurosci 118: 63-78.

Meijer OC (2002). Coregulator proteins and corticosteroid action in the brain. J Neuroendocrinol 14: 499-505.

Mickley GA, Ferguson JL, Mulvihill MA, Nemeth TJ (1989). Progressive behavioral changes during the maturation of rats with early radiation-induced hypoplasia of fascia dentata granule cells. Neurotoxicol Teratol 11: 385-393.

Murphy MP, Rick JT, Milgram NW, Ivy GO (1995). A simple and rapid test of sensorimotor function in the aged rat. Neurobiol Learn Mem 64: 181-186.

Neal Jr CR, Weidemann G, Kabbaj M, Vazquez DM (2004). Effect of neonatal dexamethasone exposure on growth and neurological development in the adult rat. Am J Physiol Regul Integr Comp Physiol 287: R375-R385.

Ng PC, Wong GW, Lam CW, Lee CH, Fok TF, Wong MY et al (1999). Effect of multiple courses of antenatal corticosteroids on pituitary-adrenal function in preterm infants. Arch Dis Child Fetal Neonatal Ed 80: F213-F216.

NIH (1994). The effect of antenatal steroids for fetal maturation on perinatal outcomes - interim draft statement. NIH Consensus Statement Online, 1994 Feb 28-Mar 2, volume 12, number 2, pp 1-24. Accessed: October 11, 2005.

NIH (2000). Antenatal corticosteroids revisited: repeat courses. NIH Consensus Statement, 2000 August 17-18, volume 17, number 2, pp 1-10. Accessed: October 11, 2005.

Onodera K, Miyazaki S, Imaizumi M, Stark H, Schunack W (1998). Improvement by FUB 181, a novel histamine H3-receptor antagonist, of learning and memory in the elevated plus-maze test in mice. Naunyn Schmiedebergs Arch Pharmacol 357: 508-513.

Pellow S, Chopin P, File SE, Briley M (1985). Validation of open: closed arm entries in an elevated plus-maze as a measure of anxiety in the rat. J Neurosci Methods 14: 149-167.

Pellow S, File SE (1986). Anxiolytic and anxiogenic drug effects on exploratory activity in an elevated plus-maze: a novel test of anxiety in the rat. Pharmacol Biochem Behav 24: 525-529.

Perrin-Wolff M, Bertoglio J, Bressac B, Bohuon C, Pallardy M (1995). Structure-activity relationships in glucocorticoidinduced apoptosis in T lymphocytes. Biochem Pharmacol 50: 103-110.

Petersen MC, Collier CB, Ashley JJ, McBride WG, Nation RL (1983). Disposition of betamethasone in parturient women after intravenous administration. Eur J Clin Pharmacol 25: 803-810.

Podhorna J, Franklin KB (1998). Lesions of the pedunclopontine tegmental nucleus increase anxiety in rats. Neuroreport 9: 17831786.
Ravizza T, Friedman LK, Moshé SL, Velîšková J (2003). Sex differences in $\mathrm{GABA}(\mathrm{A})$ ergic system in rat substantia nigra pars reticulata. Int J Dev Neurosci 21: 245-254.

Ravizza T, Galanopoulou AS, Velíšková J, Moshé SL (2002). Sex differences in androgen and estrogen receptor expression in rat substantia nigra during development: an immunohistochemical study. Neuroscience 115: 685-696.

Reznikov AG, Nosenko ND, Tarasenko LV (1999). Prenatal stress and glucocorticoid effects on the developing gender-related brain. J Steroid Biochem Mol Biol 69: 109-115.

Richichi C, Lin EJ, Stefanin D, Colella D, Ravizza T, Grignaschi G et al (2004). Anticonvulsant and antiepileptogenic effects mediated by adeno-associated virus vector neuropeptide $\mathrm{Y}$ expression in the rat hippocampus. J Neurosci 24: 30513059.

Sajdyk TJ, Vandergriff MG, Gehlert DR (1999). Amygdalar neuropeptide Y Y1 receptors mediate the anxiolytic-like actions of neuropeptide $\mathrm{Y}$ in the social interaction test. Eur J Pharmacol 368: 143-147.

Scheepens A, van de Waarenburg M, van den Hove D, Blanco CE (2003). A single course of prenatal betamethasone in the rat alters postnatal brain cell proliferation but not apoptosis. J Physiol 552: 163-175.

Schmand B, Neuvel J, Smolders-de Haas H, Hoeks J, Treffers PE, Koppe JG (1990). Psychological development of children who were treated antenatally with corticosteroids to prevent respiratory distress syndrome. Pediatrics 86: 58-64.

Seckl JR (2000). Antenatal glucocorticoid therapy: a caveat to the applause. Clin Sci (Colch) 98: 127-128.

Seckl JR, Cleasby M, Nyirenda MJ (2000). Glucocorticoids, 11betahydroxysteroid dehydrogenase, and fetal programming. Kidney Int 57: 1412-1417.

Smith JT, Waddell BJ (2000). Increased fetal glucocorticoid exposure delays puberty onset in postnatal life. Endocrinology 141: 2422-2428.

Smolders-de Haas H, Neuvel J, Schmand B, Treffers PE, Koppe JG, Hoeks J (1990). Physical development and medical history of children who were treated antenatally with corticosteroids to prevent respiratory distress syndrome: a 10- to 12 -year followup. Pediatrics 86: 65-70.

Sorensen G, Lindberg C, Wortwein G, Bolwig TG, Woldbye DP (2004). Differential roles for neuropeptide Y Y1 and Y5 receptors in anxiety and sedation. J Neurosci Res 77: 723-729.

Stenzel-Poore MP, Heinrichs SC, Rivest S, Koob GF, Vale WW (1994). Overproduction of corticotropin-releasing factor in transgenic mice: a genetic model of anxiogenic behavior. $J$ Neurosci 14: 2579-2584.

Stott DH (1973). Follow-up study from birth of the effects of prenatal stresses. Dev Med Child Neurol 15: 770-787.

Takahashi LK, Turner JG, Kalin NH (1998). Prolonged stressinduced elevation in plasma corticosterone during pregnancy in the rat: implications for prenatal stress studies. Psychoneuroendocrinology 23: 571-581.

Tamvakopoulos CS, Neugebauer JM, Donnelly M, Griffin PR (2002). Analysis of betamethasone in rat plasma using automated solid-phase extraction coupled with liquid chromatography-tandem mass spectrometry. Determination of plasma concentrations in rat following oral and intravenous administration. J Chromatogr B 776: 161-168.

Thorsell A, Michalkiewicz M, Dumont Y, Quirion R, Caberlotto L, Rimondini $\mathrm{R}$ et al (2000). Behavioral insensitivity to restraint stress, absent fear suppression of behavior and impaired spatial learning in transgenic rats with hippocampal neuropeptide Y overexpression. Proc Natl Acad Sci USA 97: 12852-12857.

Treit D, Pesold C, Rotzinger S (1993). Noninteractive effects of diazepam and amygdaloid lesions in two animal models of anxiety. Behav Neurosci 107: 1099-1105. 
Tronche F, Kellendonk C, Kretz O, Gass P, Anlag K, Orban PC et al (1999). Disruption of the glucocorticoid receptor gene in the nervous system results in reduced anxiety. Nat Genet 23: 99-103.

Tschenett A, Singewald N, Carli M, Balducci C, Salchner P, Vezzani A et al (2003). Reduced anxiety and improved stress coping ability in mice lacking NPY-Y2 receptors. Eur J Neurosci 18: 143-148.

Vallee M, MacCari S, Dellu F, Simon H, Le Moal M, Mayo W (1999). Long-term effects of prenatal stress and postnatal handling on age-related glucocorticoid secretion and cognitive performance: a longitudinal study in the rat. Eur J Neurosci 11: 2906-2916.

Vallee M, Mayo W, Dellu F, Le Moal M, Simon H, Maccari S (1997). Prenatal stress induces high anxiety and postnatal handling induces low anxiety in adult offspring: correlation with stressinduced corticosterone secretion. J Neurosci 17: 2626-2636.

Velíšek L (2005a). Prenatal corticosteroid impact on hippocampus: implications for postnatal outcomes. Epilepsy Behav 7: 57-67.
Velíšek L (2005b). Prenatal betamethasone exposure suppresses kindling epileptogenesis in immature rats. In: Corcoran ME, Moshé SL (eds). Kindling 6. Springer: New York. pp 11-17.

Welberg LAM, Seckl JR (2001). Prenatal stress, glucocorticoids and the programming of the brain. J Neuroendocrinol 13: 113-128.

Welberg LAM, Seckl JR, Holmes MC (2001). Prenatal glucocorticoid programming of brain corticosteroid receptors and corticotrophin-releasing hormone: possible implications for behaviour. Neuroscience 104: 71-79.

Welberg LAM, Seckl JR, Holmes MC (2000). Inhibition of $11 \beta$ hydroxysteroid dehydrogenase, the foeto-placental barrier to maternal glucocorticoids, permanently programs amygdala GR mRNA expression and anxiety-like behaviour in the offspring. Eur J Neurosci 12: 1047-1054.

Yan XX, Toth Z, Schultz L, Ribak CE, Baram TZ (1998). Corticotropin-releasing hormone $(\mathrm{CRH})$-containing neurons in the immature rat hippocampal formation: light and electron microscopic features and colocalization with glutamate decarboxylase and parvalbumin. Hippocampus 8: 231-243. 